\title{
Dielectric Properties and Coulomb Blockade Effect in Nano-Ag/Silicone Resin Modified Polyester Composite
}

\author{
Xiaobing Dong Non-member (Shanghai Jiao Tong University, Shanghai, 200240, China) \\ Yi Yin Non-member (Shanghai Jiao Tong University, Shanghai, 200240, China) \\ Xiuchen Jiang Non-member (Shanghai Jiao Tong University, Shanghai, 200240, China)
}

Keywords : nano-Ag, silicone resin modified polyester, nanocomposite, coulomb blockade effect

Silicone resin modified polyester (SP) was used as the high resistivity polymer, in which nano-Ag was blended. Nano-Ag/SP composite were made by utilizing sol-gel solution. The microstructure of the composite was characterized and the dielectric properties were measured to check the effects of metal nano-particle on the composite.

$\mathrm{AgNO}_{3}$ was dissolved in $\mathrm{N}, \mathrm{N}$ - dimethylformamide to make the $\mathrm{AgNO}_{3}$ solution $(0.001 \mathrm{M})$. With the sunlight, the color of solution changed from weak tawny to light brown after 5 hours and the Ag colloidal sols can be achieved.

After weighing out ultra pure SP and Ag colloidal sols with graduated cylinder, they were mixed and stirred by using stirring rod first and then treated by ultrasonicator.

From the TEM photo shown in Fig.1, the size of nano $\mathrm{Ag}$ particles is about $15 \sim 20 \mathrm{~nm}$ and nano-Ag disperses uniformly in the composite.

From Table 1, the resistivities of the composite films are about

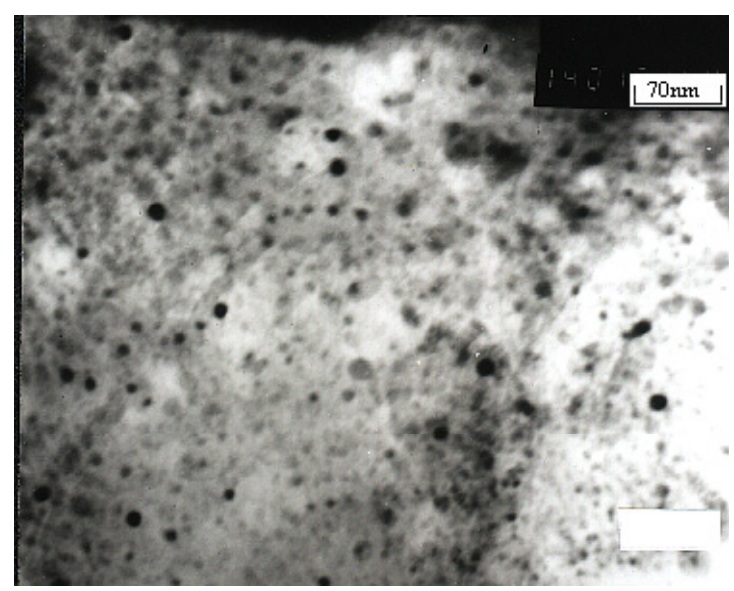

Fig. 1. TEM photo of dispersion of nano-Ag in SP ( before solidification)
7 times larger than the pure SP at cryogenic temperature. However, at room temperature those are almost same to each other. It might be easier to meet the conditions of $e^{2} / 2 C>>k_{\mathrm{B}} T$ (Coulomb Blockade effect) at lower temperature, and prevention of nano metal particles to charge carrier is prominent.

The breakdown field of the composite increases and the maximal breakdown field of the composite is $112 \%$ of that of pure SP. The increases of dielectric relative permittivity of the composite become obviously when the content of nano-Ag in the composite and then decrease when the measuring frequency increases in full frequency spectra. The $\tan \delta$ increases as the content of nano-Ag increases. DSC spectra was taken under the atmosphere, and temperature rising speed was $5 \mathrm{~K} / \mathrm{min}$ from $298 \mathrm{~K}\left(25^{\circ} \mathrm{C}\right)$ to $523 \mathrm{~K}\left(250^{\circ} \mathrm{C}\right)$. There is no melting peak and thermal decomposition for both kinds of samples. In the temperature range we concerned, pure SP and nano-Ag/SP composite have no phase change and keep the same thermal stability.

TSDC spectra indicates that there are two low trap levels in the nano-Ag/SP composite and the stimulation temperatures are $321 \mathrm{~K}$ and $358 \mathrm{~K}$, respectively. The traps with energy level and trap concentration are $0.52 \mathrm{eV} 1.2 \times 10^{10} / \mathrm{cm}^{3}$ and $0.62 \mathrm{eV} 2.0 \times$ $10^{11} / \mathrm{cm}^{3}$ respectively.

Table 1. Resistivity of nano-Ag/SP composite

\begin{tabular}{cccc}
\hline sample & $\begin{array}{c}\text { Film } \\
\text { Thickness } \\
(\mathrm{mm})\end{array}$ & $\begin{array}{c}\text { Resistivity } \\
(297 \mathrm{k}) / 10^{17} \Omega \cdot \mathrm{cm}\end{array}$ & $\begin{array}{c}\text { Resistivity } \\
(77 \mathrm{k}) / 10^{18} \Omega \cdot \mathrm{cm}\end{array}$ \\
\hline SP & 0.127 & 1.21 & 0.931 \\
$1^{\#}$ & 0.129 & 0.583 & 1.35 \\
$2^{\#}$ & 0.121 & 0.691 & 2.63 \\
$3^{\#}$ & 0.135 & 0.97 & 7.30 \\
$4^{\#}$ & 0.133 & 0.638 & 7.13 \\
$5^{\#}$ & 0.123 & 1.01 & 5.89 \\
\hline $6^{\#}$ & 0.129 & 1.08 & 6.22 \\
\hline
\end{tabular}




\title{
Dielectric Properties and Coulomb Blockade Effect in Nano-Ag/Silicone Resin Modified Polyester Composite
}

\author{
Xiaobing Dong* Non-member \\ Yi Yin* Non-member \\ Xiuchen Jiang* Non-member
}

\begin{abstract}
In order to modify material properties, nano $\mathrm{Ag}$ (diameter less than $20 \mathrm{~nm}$ ) was successfully made from Ag colloidal sol and uniformly dispersed into silicone resin modified polyester (SP). The dielectric properties of the composite were studied. Resistivity- temperature characteristic of the composite is some different from that of pure SP. The maximal breakdown voltage of the composite is $112 \%$ of that of pure SP and dielectric loss can be 8 times of pure SP at power frequency. Dielectric constants of the composites all increased with various contents of nano Ag. Two types of shallow traps $(0.52 \mathrm{eV}$ and $0.62 \mathrm{eV})$ with trap densities $\left(1.2 \times 10^{10} / \mathrm{cm}^{3}\right.$ and $\left.2.0 \times 10^{11} / \mathrm{cm}^{3}\right)$ are found in the composite, which differs from those of pure SP $(0.58 \mathrm{eV}, 3.1 \times$ $10^{10} / \mathrm{cm}^{3}$ ) significantly. Resistivity of the composite is much greater than that of pure SP under cryogenic temperature (77K), which might be treated as the result of Coulomb Blockade effect. From the view of dielectric physics, the different characteristic between the composite and pure SP was discussed and a new concept of nano metal/dielectric materials composite used for device surface protection was introduced.
\end{abstract}

Keywords : nano-Ag, silicone resin modified polyester, nanocomposite, coulomb blockade effect

\section{Introduction}

The mechanical, magnetic, optical and dielectric properties of polymer/inorganic nano-composite have been a very attractive research frontier of nano-science. As regards to those of traditional polymer/inorganic particles composites, the development potential of the nano-composites in mechanical, chemical, environmental and electrical utilization gives the researchers more attractive exploring fields.

Nanometer-dimension metal particles are provided with a number of special physical and chemical properties for their special microstructures, such as quantum-size effects ${ }^{(1)}$, small-size effects, surface effects and macro-quantum tunneling effects etc, which are very different from those of general size metal particles. For example, metal nano-particles can exhibit insulating property at low temperature; showing some peculiar dielectric properties. 'Coulomb blockade'(2) is one of most important effects due to nano-particles, which gives us a new idea about designing new nano- composite as insulating material.

Composite materials containing metal nano-particles, immobilized in polymer matrices are under intense studies due to fundamental novelty and technological importance. There are different ways to produce such materials: treatment of polymers by metal vapours; reduction of metal salts or their reactions in polymer solutions; incorporation of metal salt solutions in micropores of stretched polymer films; various polymerization processes of metal-containing monomer systems, sol-gel solution containing metal nano-particle et $\mathrm{al}^{(3)-(4)}$.

In this paper, silicone resin modified polyester $(\mathrm{SP})^{(5)-(6)}$ was used as the high resistivity polymer, in which nano-Ag was blended. Nano-Ag/SP composite were made by utilizing sol-gel

\footnotetext{
* Department of Electrical Engineering, Shanghai Jiao tong University
}

Dongchuan Road 800, Minhang, Shanghai, China 200240 solution $^{(7)}$. The microstructure of the composite was characterized and the dielectric properties were measured to check the effects of metal nano-particle on the composite.

\section{Experimental Procedures}

Nano-metal particle has high surface energy and surfactivity, which make it easy to aggregate and cause chemical reaction. If aggregation happens, the nano-metal particle will lose its special nano properties. The key point to prepare nano-metal/polymer composite is how to disperse the nano-metal uniformly into the polymer matrix.

At first, $\mathrm{AgNO}_{3}$ was dissolved in $\mathrm{N}, \mathrm{N}$ - dimethylformamide to make the $\mathrm{AgNO}_{3}$ solution $(0.001 \mathrm{M})$. With the sunlight, the color of solution changed from weak tawny to light brown after 5 hours and the Ag colloidal sols can be achieved. Strong light should be avoided during this process and the solution should been taken away to the dark place before the color of solution changes to fuscous.

After weighing out ultra pure SP and Ag colloidal sols with graduated cylinder, they were mixed and stirred by using stirring rod first and then treated by ultrasonicator. Table 1 gives the different kinds of samples' content of Ag colloidal sols in SP.

The mixed solution was desiccated in vacuum oven at $358 \mathrm{~K}$, vaporizing a given mass of solvent to make the solution keeping certain viscosity. The time for this process is adjusted according to the content of $\mathrm{Ag}$ colloidal sols. Nano-Ag/SP solution was deposited on a substrate of rose copper by whirl coating method.

Table 1. Content of Ag colloidal sols in SP

\begin{tabular}{ccccccc}
\hline Sample & $1 \#$ & $2 \#$ & $3 \#$ & $4 \#$ & $5 \#$ & $6 \#$ \\
\hline $\begin{array}{c}\text { Ag colloidal } \\
\text { sols } / \mathrm{mL}\end{array}$ & 0.5 & 5 & 15 & 20 & 30 & 40 \\
\hline $\mathrm{SP} / \mathrm{mL}$ & 20 & 20 & 20 & 20 & 20 & 20 \\
\hline
\end{tabular}




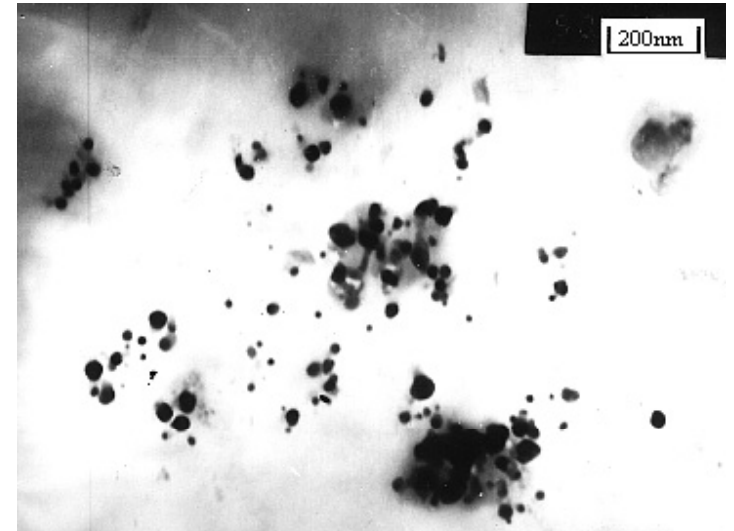

Fig. 1. TEM photo of Ag colloidal sols film forming in collodion

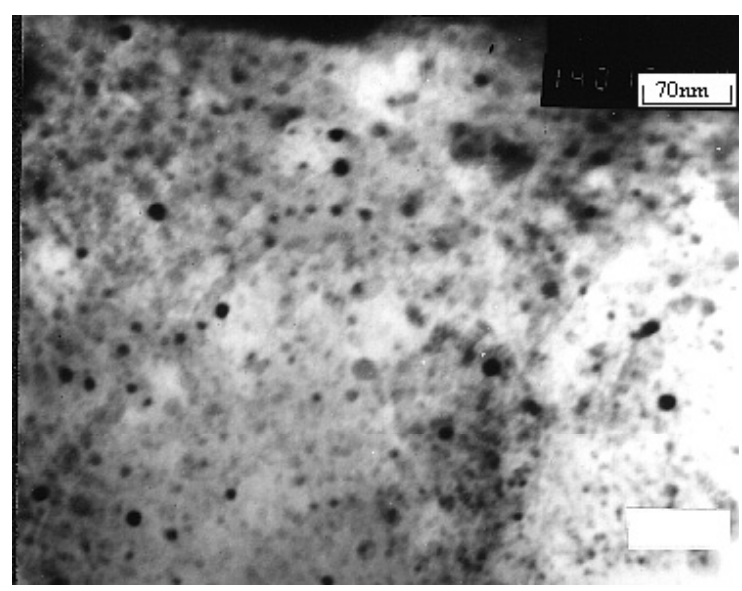

Fig. 2. TEM photo of dispersion of nano-Ag in SP (before solidification)

The samples were solidified according to three steps: placement at room temperature, drying at low temperature and solidification at high temperature. The drying process for the nano- $\mathrm{Ag} / \mathrm{SP}$ solution may take more time than that of pure SP to remove the solvent completely.

The thickness of the copper substrate was $0.3 \mathrm{~mm}$ and aluminum foil with thickness $40 \mu \mathrm{m}$ was used as upper electrode, which were combined as triple-electrode for bulk resistivity measurement.

After solidification, the composite samples' thickness were measured and recorded. To cooperate with the measurement at cryogenic temperature, another kind of sample size was also made by using steel die $(\Phi 100 \mathrm{~mm} \times 1 \mathrm{~mm})$.

The structure and dispersion analyses of Ag colloidal sols and nano-Ag/SP solution (or composite) were carried out by using JEM - 200CX Transmission Electron Microscope (TEM). The membrane TEM photo of Ag colloidal sols film forming in collodion is shown in Fig.1. Although this kind of film forming has some influence on the dispersion of nano-Ag, the size of the nano-Ag particles is about $10 \sim 20 \mathrm{~nm}$. The stability of the $\mathrm{Ag}$ colloidal sols can keep for several days, which is convenient for the composite use.

The dispersion analyses of nano-Ag/SP solution (before solidification) and nano-Ag/SP composite (after solidification) were shown in Fig.2 and Fig.3. From the TEM photos, the size of nano $\mathrm{Ag}$ particles is about $15 \sim 20 \mathrm{~nm}$ and nano- $\mathrm{Ag}$ disperses

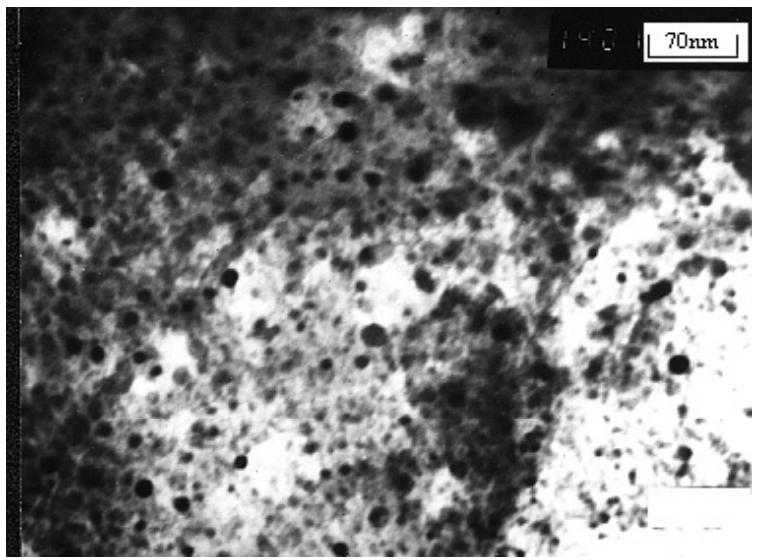

Fig. 3. TEM photo of dispersion of nano-Ag in SP (after solidification)

uniformly in the composite.

The concentration of $\mathrm{AgNO}_{3}$ and the illumination degree of sunlight are used to control the size of nano-Ag particles. Long term concentrating in vacuum at low temperature has not changed the size of nano-Ag but the content in the composite. The uniform dispersion of nano-Ag in the composite is guaranteed by the long term stirring and ultrasonicator treatment ${ }^{(7)}$.

The samples' bulk resistivity was measured by utilizing ZC-36 high resistance meter. The dielectric relative permittivity and $\tan \delta$ were measured by TR-10C Dielectric Loss Measuring Set and HIOKI 3532-50 LCR HiTESTER. The breakdown field measurement was carried out by using GYD-5/15 Automatic Voltage Test. The cryogenic temperature test used liquid nitrogen at $77 \mathrm{~K}$.

\section{Results and Discussion}

The curves of $\log \rho_{v}-1 / T$ were shown in Fig.4. The temperature range was from $291 \mathrm{~K}$ to $473 \mathrm{~K}$.

From the Fig.4, the resistivity of the composite is close to that of pure SP at room temperature and the decrease trend of the resistivity at high temperature becomes slow. With the content of nano-Ag increasing, the resistivity of the composite changes. When the content of nano-Ag in the composite is about (5 8) $\times$ $10^{-5} w t$ (sample $3 \#$ and $4 \#$ ), the resistivity of the composite is higher than that of pure SP in a small degree while the temperature is above $423 \mathrm{~K}$.

Table 2 gives the resistivity of nano-Ag/SP composite at $293 \mathrm{~K}$ and cryogenic temperature $(77 \mathrm{~K})$.

From Table 2, the resistivities of $3 \#$ and $4 \#$ composite films are about 7 times larger than that of pure SP at cryogenic temperature. However, at room temperature those are almost same to each other.

Table 3 gives the breakdown properties of nano- $\mathrm{Ag} / \mathrm{SP}$ composite films. The breakdown field of the composite increases and the maximal breakdown field of the composite is $112 \%$ of that of pure SP.

The dielectric relative permittivity and $\tan \delta$ were measured, as shown in Fig. 5 and Fig. 6 respectively. The increases of dielectric relative permittivity of the composite become obviously when the content of nano- Ag in the composite and then decrease when the measuring frequency increases in full frequency spectra. The $\tan \delta$ increases as the content of nano-Ag increases. When the frequency is above $100 \mathrm{kHz}$, this increase become distinct and larger. Tan $\delta$ 

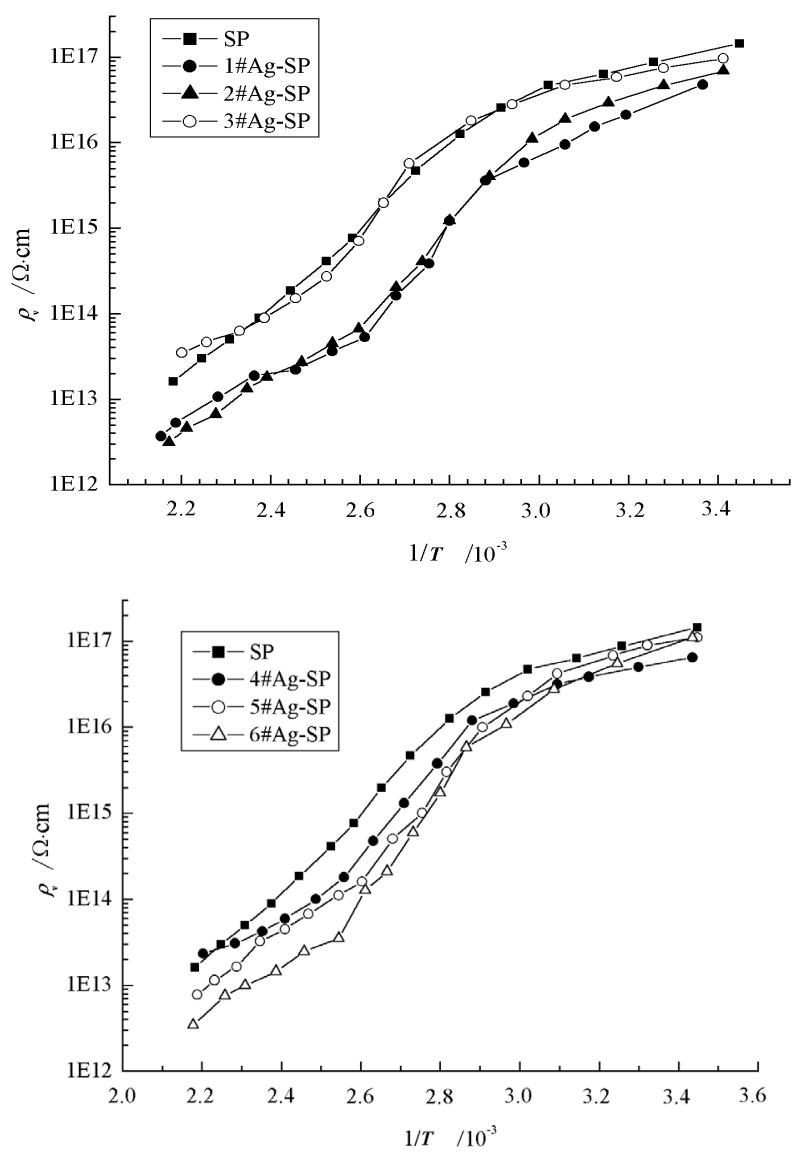

Fig. 4. $\log \rho_{v}-1 / T$ characteristic of nano-Ag/SP composite

Table 2. Resistivity of nano-Ag/SP composite

\begin{tabular}{cccc}
\hline sample & $\begin{array}{c}\text { Film } \\
\text { Thickness } \\
(\mathrm{mm})\end{array}$ & $\begin{array}{c}\text { Resistivity } \\
(297 \mathrm{k}) / 10^{17} \Omega \cdot \mathrm{cm}\end{array}$ & $\begin{array}{c}\text { Resistivity } \\
(77 \mathrm{k}) / 10^{18} \Omega \cdot \mathrm{cm}\end{array}$ \\
\hline SP & 0.127 & 1.21 & 0.931 \\
$1^{\#}$ & 0.129 & 0.583 & 1.35 \\
$2^{\#}$ & 0.121 & 0.691 & 2.63 \\
$3^{\#}$ & 0.135 & 0.97 & 7.30 \\
$4^{\#}$ & 0.133 & 0.638 & 7.13 \\
$5^{\#}$ & 0.123 & 1.01 & 5.89 \\
\hline $6^{\#}$ & 0.129 & 1.08 & 6.22 \\
\hline
\end{tabular}

Table 3. Breakdown voltage of nano-Ag/SP composite

\begin{tabular}{cccccccc}
\hline Sample & SP & $1^{\#}$ & $2^{\#}$ & $3^{\#}$ & $4^{\#}$ & $5^{\#}$ & $6^{\#}$ \\
$\begin{array}{c}\text { Thickness } \\
/ \mathrm{mm}\end{array}$ & 0.427 & 0.522 & 0.421 & 0.475 & 0.513 & 0.506 & 0.459 \\
$\begin{array}{c}E_{\mathrm{B}} \\
/ \mathrm{kV} \cdot \mathrm{mm}^{-1}\end{array}$ & 91.1 & 93.4 & 95.2 & 97.8 & 96.1 & 102.6 & 96.6 \\
\hline
\end{tabular}

can be 8 times of pure SP at power frequency. This can be explained as the result of residuum of colloidal sols, which adds the polar impurities into the composite.

Differential Scanning Calorimeter (DSC) analysis of the pure SP and nano-Ag/SP composite is shown in Fig.7, by using METTLER TOLEDO DSC823e .

DSC spectra was taken under the atmosphere, and temperature rising speed was $5 \mathrm{~K} / \mathrm{min}$ from $298 \mathrm{~K}\left(25^{\circ} \mathrm{C}\right)$ to $523 \mathrm{~K}\left(250^{\circ} \mathrm{C}\right)$. There is no melting peak and thermal decomposition for both kinds of samples. In the temperature range we concerned, pure SP

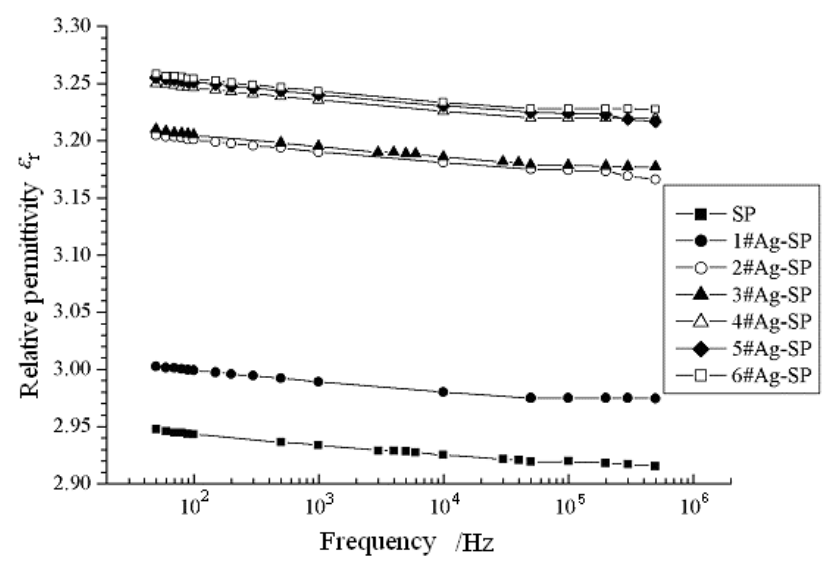

Fig. 5. Dielectric relative permittivity of the nano-Ag/SP composite

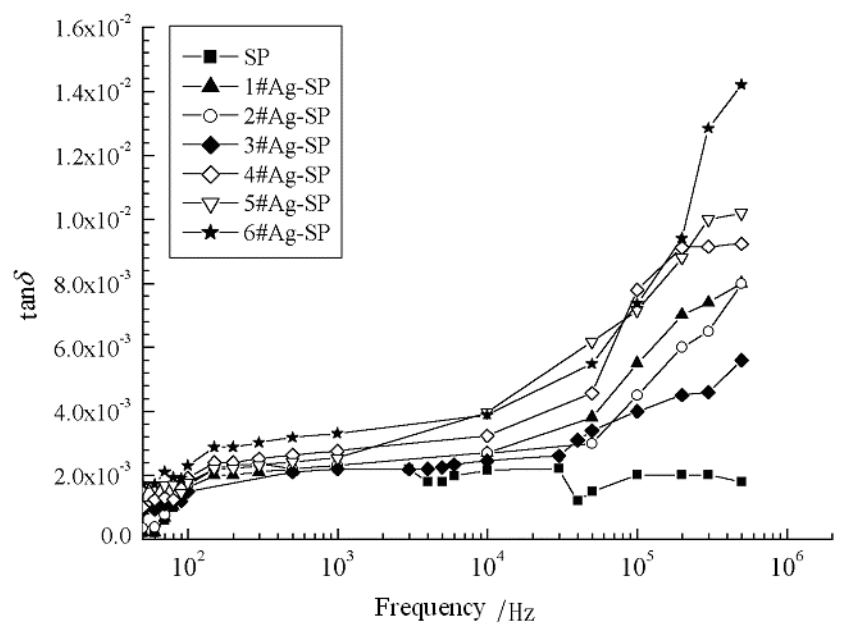

Fig. 6. Tan $\delta$ spectra of the nano-Ag/SP composite

and nano- $\mathrm{Ag} / \mathrm{SP}$ composite have no phase change and keep the same thermal stability.

Thermally Stimulated Depolarization Current (TSDC) analysis was carried out by using our Lab instruments. Sample size was $\Phi 30 \mathrm{~mm}$, with vaporized $\mathrm{Al}$ electrode $(\Phi 20 \mathrm{~mm})$ on both sides. Sample thickness of pure SP and nano-Ag/SP composite were $118 \mu \mathrm{m}$ and $122 \mu \mathrm{m}$, respectively. All the samples were short-circuited in a vacuum oven at $10^{-2} \mathrm{~Pa}$ and $373 \mathrm{~K}$ for $24 \mathrm{~h}$. Then the samples were placed in the measurement chamber, polarizing for $1 \mathrm{~h}$ with the polarization voltage $900 \mathrm{~V}$ and temperature $373 \mathrm{~K}$. Keeping the polarization voltage, the samples were quickly refrigerated to $223 \mathrm{~K}$. Temperature rising speed was $2 \mathrm{~K} / \mathrm{min}$ during thermal stimulation process.

The TSDC spectra are shown in Fig.8, which indicate that there are two low trap levels in the nano-Ag/SP composite and the stimulation temperatures are $321 \mathrm{~K}$ and $358 \mathrm{~K}$, respectively. The traps with energy level and trap concentration are $0.52 \mathrm{eV} 1.2 \times$ $10^{10} / \mathrm{cm}^{3}$ and $0.62 \mathrm{eV} 2.0 \times 10^{11} / \mathrm{cm}^{3}$ respectively. We have known that there is a trap level with energy level $0.58 \mathrm{eV}$ and trap concentration $3.1 \times 10^{10} / \mathrm{cm}^{3}$ in pure SP. It can be seen that many traps are inducted into the composite because of the adulteration of nano-Ag into SP. The concentration of this kind of traps is about 10 times of that of pure SP.

As is now well known, while the size of a metal particle is small enough to make its capacitance $(C)$ to outer arrive to $10^{-16} \mathrm{~F}$, 


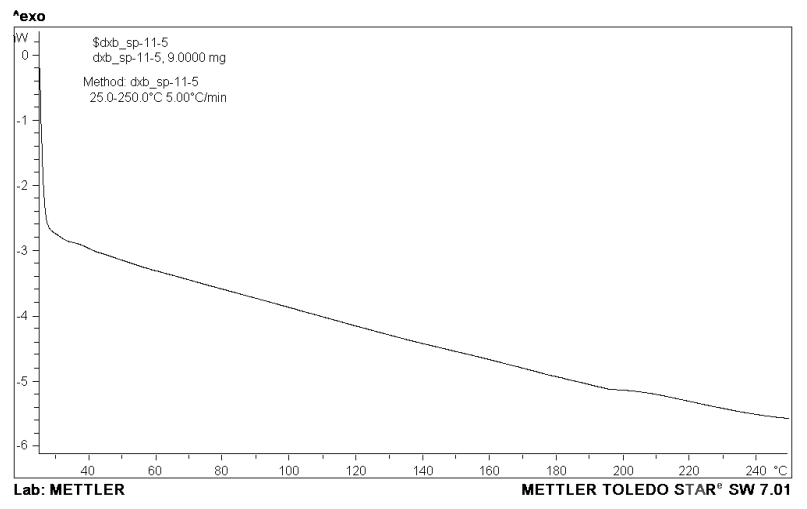

(a) Pure SP

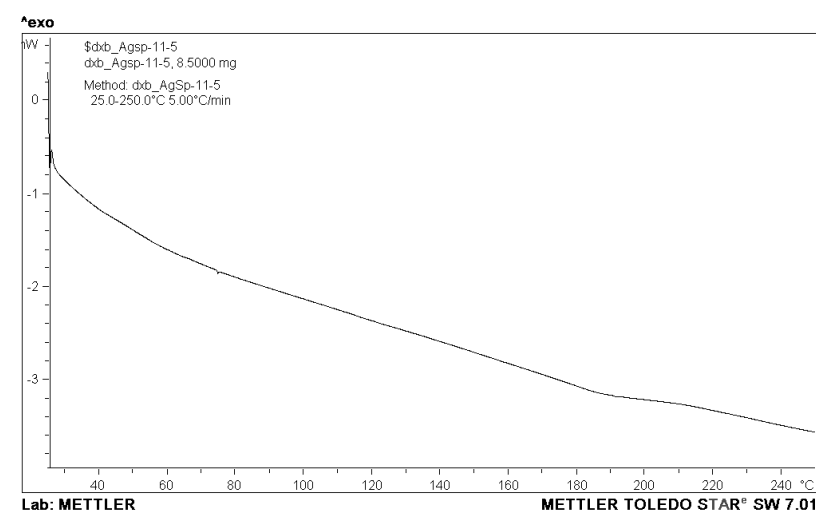

(b) Nano-Ag/SP composite

Fig. 7. DSC spectra of pure $\mathrm{SP}$ and nano-Ag/SP composit

when a single electron tunnels into the particle from outer, it can append charge energy $e / C$ ( $e$ is electron electricity quantity), which is far more than the energy of thermal motion $k_{\mathrm{B}} T\left(k_{\mathrm{B}}\right.$ is the Boltsman Constant) at cryogenic temperature. In the conditions which satisfy the requirement $e^{2} / 2 C>>k_{\mathrm{B}} T$, i.e. electrostatic energy is far greater than the influence of thermal fluctuation of electrons, a single electron tunneled into the particle from outer will inhibit the later electron tunneling into the metal particle. This is called 'Coulomb blockade effect'.

When the content of nano-Ag (with size 15 20nm) is about $(5 \sim 8) \times 10^{-5} w t$, the resistivity of nano-Ag/SP composite is about 7 times larger than that of pure SP at cryogenic temperature. Maybe at this Ag concentration range, it is easier to meet the conditions of $e^{2} / 2 C>>k_{\mathrm{B}} T$ at lower temperature and prevention of nano metal particles to charge carrier is prominent, which increases the resistivity of the composite. As the content of nano-Ag increases more than $10^{-4} \mathrm{wt}$, Ag particles in $\mathrm{SP}$ matrix show some agglomeration and particle size become bigger, which increases the capacitance between metal particles obviously and the Coulomb blockade effects become weak.

The uniform dispersion of nano-Ag in the composite can decrease the free path of electron and increase the scatter probability, which decreases the kinetic energy of electron and prevents the charge carrier of the whole system from moving directionally by the action of electric field. The breakdown field strength of the composite improves. It seems that this improvement is not so remarkable as the results acquired by Feng ${ }^{(8)}$, it might because SP is very different from polyvinyl alcohol (PVA).

The adding of nano-Ag into SP brings two shallow trap levels and the concentration of the traps is higher than that of pure SP,

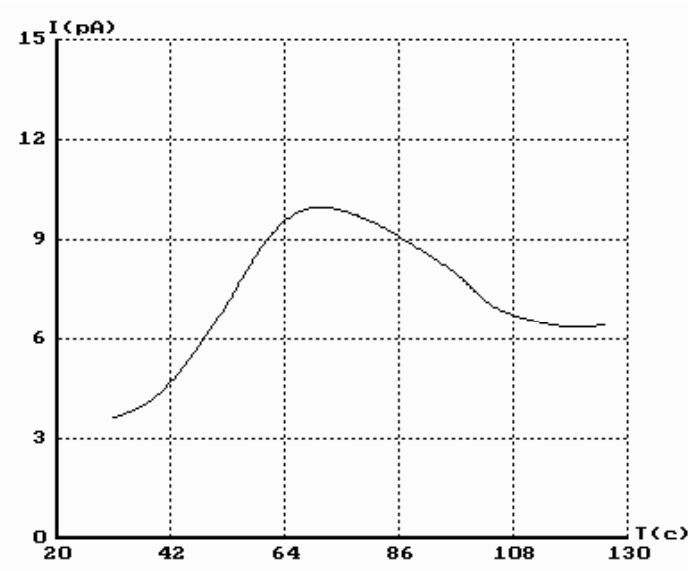

(a) TSDC result of pure SP : $I_{\max }=9.9 \mathrm{pA}, T_{\max }=344 \mathrm{~K}\left(71^{\circ} \mathrm{C}\right)$, trap level $E=0.58 \mathrm{eV}$, trap concentration $\mathrm{n}=3.1 \times 10^{10} / \mathrm{cm}^{3}$

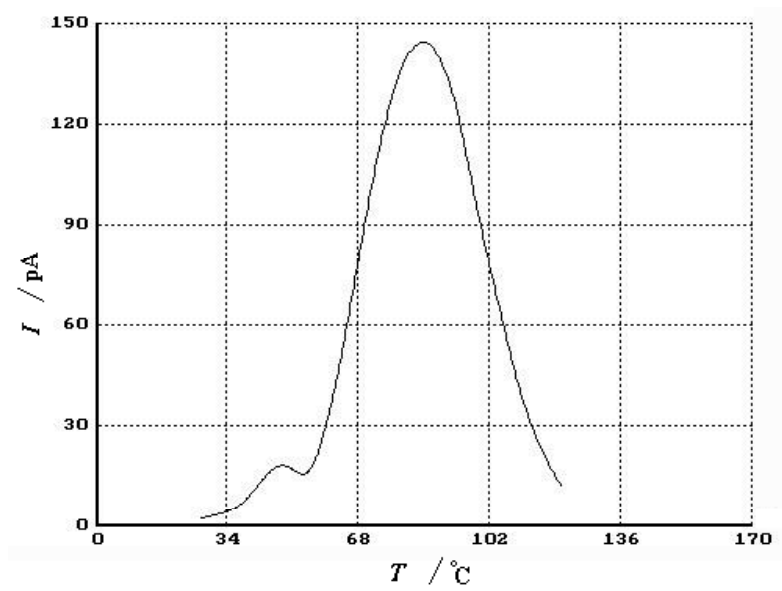

(b) TSDC results of nano-Ag/SP composite : $I_{\max 1}=17.6 \mathrm{pA}, T_{\max 1}=321 \mathrm{~K}$ $\left(48^{\circ} \mathrm{C}\right)$, trap level $\mathrm{E}_{1}=0.52 \mathrm{eV}$, trap concentration $\mathrm{n}_{1}=1.2 \times 10^{10} / \mathrm{cm}^{3}$; $I_{\max 2}=144.2 \mathrm{pA}, \quad T_{\max 2}=358 \mathrm{~K}\left(85^{\circ} \mathrm{C}\right)$, trap level $E_{2}=0.62 \mathrm{eV}$, trap concentration $\mathrm{n}_{2}=2.0 \times 10^{11} / \mathrm{cm}^{3}$

Fig. 8. TSDC results of pure SP and nano-Ag/SP composite

which can be regarded as the main influence to the dielectric spectra properties of the composite.

SP is always used as power devices' surface protection material, with high resistivity and high temperature stability. It is inclined to positively charged and the impurity cation will aggregate near cathode when temperature is higher enough, which deteriorates the local high field and brings to local breakdown. Nano-Ag used here might bring some active influence on the limitation of cation's directional movement and aggregation under electrical field ${ }^{(9)}$. By understanding the effects of nano-sized metal particles on dielectric properties of polymer composites, it is potential to develop advanced materials for electronic packaging applications with enhanced performance, e.g., electrification restraining property, ion block under high temperature and better dielectric characteristics under wide temperature and frequency range.

\section{Conclusions}

Nano-Ag particles with size 10 20nm can be prepared under proper conditions by sol-/gel process and dispersed uniformly into SP. The nano Ag content in the composite is very low and the content of nano $\mathrm{Ag}$ in the composite is less than $10^{-4} \mathrm{wt}$.

At cryogenic temperature, the resistivity of the nano-Ag/SP composite increases much than that of pure SP, which might be 
treated as the results of 'Coulomb blockade effect'. The dielectric relative permittivity of the composite decreases when measuring frequency increases in full frequency spectra. The tan $\delta$ increases as the content of nano-Ag increases. When the frequency is above $100 \mathrm{kHz}$, this increase become distinct and larger.

There are two low trap levels in the nano-Ag/SP composite and larger trap concentration is inducted into the composite because of the adulteration of nano-Ag into SP.

\section{Acknowledgement}

The authors wish to thank State Key Laboratory of Electrical Insulation and Power Equipment (Xi'an Jiaotong University) for facilities of the test equipments and great help from the faculties.

(Manuscript received Feb. 2, 2006, revised June 14, 2006)

\section{References}

(1) A. Henglein : "Small-particle research: physicochemical properties of extremely small colloidal metal and semiconductor particles", Chem. Rev., Vol.37, pp.1861-1873 (1989)

(2) K. A. Matveev, L. I. Glazman, and H. U. Baranger : "Theory of Coulomb blockade of tunneling through a double quantum dot", Surface Science, Vol.361-362, pp.623-626 (1996)

(3) L. I Trakhtenberg, E. Axelrod, G. N. Gerasimov, et al. : "New nanocomposite metal-polymer materials: Dielectric behaviour", $J$. Non-Crystalline Solids, Vol.305, pp.190-196 (2002)

(4) A. B. R. Mayer : "Colloidal metal nanoparticles dispersed in amphiphilic polymers", Polym. Adv. Technol., Vol.12, pp.96-106 (2001)

(5) H. Wang and C. Xu : "Study on conduction mechanism of SP for electronic device surface passivation", Power Electronics, Vol.27, pp.27-32 (1993)

(6) X. Dong and C. Xu. : "Research on the electrification of surface protective materials used in power electronic devices", 2000 ICPADM, pp.978-982, Xi'an, China (2002)

(7) K. Okuyama, W. Lenggoro, and T. Iwaki : "Nanoparticle preparation and its application - a nanotechnology particle project in Japan", 2004 ICMENS, pp.369-372, Banff, Alberta Canada (2004)

(8) J. Feng, M. Xu, et al : "The preparation and electrical property of Ag/PVA nano-polymer matrix composite", Proc. Chinese Soc. Electrical Engineering, Vol.24, pp.92-95 (2004)

(9) L. Fan, B. Su, J. Qu, and C. P. Wong : "Effects of nano-sized particles on electrical and thermal conductivities of polymer composites" 2004 Proc. of the 9th International Symposium on Advanced Packaging Materials: Processes, Properties and Interfaces, pp.193-199, Atlanta, Georgia U.S.A. (2004)

Xiaobing Dong

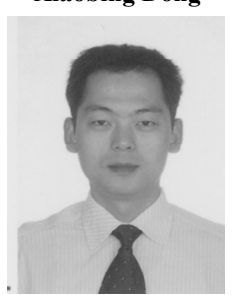

Yi Yin

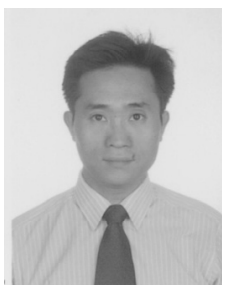

(Non-member) was born in Shaanxi province, China on Feb. 13, 1973. He Received a Ph. D. degree in electrical engineering from Xi'an Jiaotong University in 2004, and is presently a postdoctoral researcher in Shanghai Jiao Tong University. He has worked on dielectric properties of polymeric nanocomposites and life evaluation for power apparatus.

(Non-member) was born in Jangsu province, China on Oct. 28, 1972. He Received a Ph. D. degree in electrical engineering from Xi'an Jiaotong University in 2000, and is presently an associate professor in Shanghai Jiao Tong University. He has worked on electrical aging of polymer insulating materials, dielectric properties of polymeric nanocomposites and monitoring on-line of power apparatus. 